\title{
R-DA-EPOCH Regimen
}

National Cancer Institute

\section{Source}

National Cancer Institute. R-DA-EPOCH Regimen. NCI Thesaurus. Code C140097.

A regimen consisting of etoposide, prednisone, vincristine, cyclophosphamide,

doxorubicin and rituximab (EPOCH-R) in a dose-adjusted (DA) version that can be used for the treatment of non-Hodgkin lymphoma (NHL). 